\title{
POLÍTICA INTERNACIONAL, DO PENSAMENTO REALISTA À TEORIA NEORREALISTA: O pensamento teórico de Hans Morgenthau e Kenneth Waltz em perspectiva comparada
}

\author{
Paulo Victor Zaneratto Bittencourt ${ }^{1}$
}

\section{Resumo:}

O objetivo do trabalho aqui apresentado é uma breve comparação entre as teorias consideradas realistas de Hans J. Morgenthau e Kenneth N. Waltz. Sabemos que o pensamento de ambos os autores se encontra em debates distintos da disciplina de relações internacionais, sendo a principal obra de Waltz, Theory of international politics, posterior à principal obra de Morgenthau, Politics among nations. Assim, buscaremos, já que ambos os autores são considerados realistas, aproximações e distanciamentos nas obras em questão, visando a melhor compreensão das ideias ditas realistas ao longo daqueles que são convencionalmente chamados debates acadêmicos da disciplina de relações internacionais. Para esse fim, utilizaremos os "seis princípios do realismo político" de Hans Morgenthau como fundamento para sua teoria, e estabeleceremos a comparação da mesma forma com Waltz, para cuja obra o fundamento tomado será o texto Man, the state, and War. O que visamos aqui, portanto, é um foco mais preciso no conjunto da obra dos dois autores, partindo da proposta de apresentarem-se "autores" em vez de "escolas de pensamento", o que nos permite um detalhamento maior dos argumentos de cada um dos pensadores.

Palavras-chave: Balança de poder, sistema internacional, estrutura internacional.

\begin{abstract}
:
The aim of this paper is a brief comparison between the considered realist theories by Hans J. Morgenthau and Kenneth N. Waltz. We know that the thought of both authors belong to distinct debates inside the discipline of international relations, being the main work of Walt's his Theory of international politics, published later than Morgenthau's Politics among nations. Once both authors are realist ones, we look for pointing the similarities and differences in both works, trying to obtain a better comprehension of the realist ideas through what are called academic debates of the discipline of international relations. Aiming at such an aim, we shall use Hans Morgenthau's "six principles of political realis" as a foundation to his theory, and we shall stablish the same comparison with Watz, for whose work will be taken as a foundation Man, the state, and war. What we aim in this paper, therefore, is a more accurate focus in the work of both authors, taking as purpose presenting authors instead of schools of thought, what allows us to a higher detailing of each author's arguments.
\end{abstract}

\footnotetext{
${ }^{1}$ Bacharel em Relações Internacionais pela Faculdade de Filosofia e Ciências da Universidade Estadual Paulista Júlio de Mesquita Filho (FFC - UNESP/Marília). Mestrando em Ciências Sociais na linha de Relações Internacionais e Desenvolvimento pela Faculdade de Filosofia e Ciências da Universidade Estadual Paulista Júlio de Mesquita Filho (FFC - UNESP/Marília). Contato: paulovbittencourt@gmail.com.
} 
Keyword: Balance of power, international system, international structure. 


\section{Introdução}

Nossa intenção neste texto é estabelecer uma comparação entre os trabalhos teóricos de Hans Joachim Morgenthau e Kenneth Neal Waltz, autores de grande importância para os estudos de teoria das Relações Internacionais. Partiremos das concepções de ambos os autores sobre o internacional e recairemos sobre a crítica feita por Kenneth Waltz sobre o realismo clássico, de que Morgenthau é o grande expoente nos Estados Unidos após a Segunda Guerra Mundial (HOFFMANN, 1963). Devido à importância que se presta à defesa e segurança nacional num ambiente internacional anárquico, estes aspectos do poder nacional acabam por ter consequências importantes na obra de ambos os autores, o que tentaremos demonstrar quando possível durante o corpo deste texto.

A partir do entendimento de Fred Halliday sobre o realismo, afirmamos que ambos os autores podem ser concebidos como realistas, já que "tomam como ponto de partida a busca do poder dos Estados, a centralidade da força militar dentro deste poder e a inevitabilidade duradoura do conflito em um mundo de múltipla soberania" (HALLIDAY, 1999, p. 24). Ainda nesse sentido, de acordo com Joseph Grieco (1993, p. 135), pontos importantes dos realistas "modernos", como Gilpin e Waltz estão em acordo com os dos realistas "clássicos", como Morgenthau, Aron e Carr: esses pontos referem-se ao papel da anarquia e como ela afeta os Estados e a possibilidade de cooperação entre eles.

Outro ponto levantado por Halliday acerca do neorrealismo é o de que ele é uma reafirmação do realismo. Há que se tomar cuidado, ao se trabalhar com o pensamento de Waltz, com tal colocação: embora em muitos pontos sejam extremamente semelhantes os pensamentos de ambos os autores com quem aqui trabalhamos, o cientista político norte-americano rejeita a ideia de que o neorrealismo seja apenas o "velho realismo tornado novo" (WALTZ, 2004, p. 3). Por outro lado, Ole Waever (2008, p. 165) diz que a ânsia por tornar suas teorias mais científicas a partir dos anos 1970, levou os realistas a deixar para trás alguns assuntos que tradicionalmente tinham em consideração, como no caso dos estadistas.

Portanto, o que tentaremos é demonstrar em cada uma das obras como as ideias dos autores se articulam e em que cada uma das abordagens, ainda que semelhantes, diferem, colocando-nos de acordo com a proposta, também de Waever (1997) de apresentar autores em vez de "paradigmas", o que nos permitiria focar muito mais claramente em características particulares dos autores. Dentro dessa linha argumentativa, portanto, falar que Morgenthau e Waltz sejam realistas porque compartilham uma série de observações como a primazia do Estado como entidade soberana, dispostos num ambiente competitivo devido aos seus 
interesses conflitantes, como afirma Mearsheimer (2002) não parece apontar para as características particulares dos autores, nem como essas possíveis convergências são articuladas em suas construções teóricas.

É indubitável que ambas os autores apresentem semelhanças, e sobre elas nos debruçaremos neste trabalho visando a elencar-lhes algumas (bem como algumas das distinções entre ambas), de maneira que não buscaremos, de forma alguma, esgotar o assunto, tendo em vista os limites deste artigo e a amplitude do debate. O que pretendemos aqui é apenas fazer com que ambos os autores dialoguem e que se estabeleçam debates através destes diálogos ${ }^{2}$.

Com este propósito, o presente trabalho está dividido como segue: num primeiro momento, seguindo uma abordagem cronológica, buscaremos a compreensão e a exposição de alguns pontos importantes do pensamento de Hans Morgenthau; a que se seguirá uma outra seção sobre o pensamento de Kenneth Waltz, com os mesmos objetivos. A partir de tais considerações, este trabalho apresentará uma seção que discutirá as semelhanças entre as obras; e uma, quase ao fim, buscando estabelecer suas distinções, incluindo aqui apontamentos feitos pelo próprio Kenneth Waltz. Finalmente, buscaremos sintetizar algumas de nossas considerações através das considerações finais, seção última deste trabalho.

\section{Hans J. Morgenthau e a busca da compreensão da política entre as nações}

Hans Joachim Morgenthau ${ }^{3}$ tem em Politics among nations sua mais conhecida contribuição para o estudo teórico das Relações Internacionais, a qual é vinculada à vertente realista da dita disciplina. Entretanto, há que se fazer uma breve advertência acerca do caráter realista de sua

\footnotetext{
${ }^{2}$ Carlos GASPAR (2013), em edição especial da revista Relações Internacionais por ocasião do falecimento de Waltz, escreve também um texto buscando comparar Morgenthau, Aron e Waltz. Para o autor, esses três teóricos formariam parte de um todo, sendo inseparáveis entre si (GASPAR, 2013, p. 5), de modo que, a partir da teorização das imagens de Waltz, poderíamos classificá-los como autores da primeira, segunda e terceira imagens, respectivamente. Os pontos abordados por Gaspar não são necessariamente os mesmos que buscaremos elencar neste texto.

3 "Nascido em Coburgo, Baviera, na Alemanha, em 17 de fevereiro de 1904, filho de médico, Morgenthau começou estudando filosofia no centro de pensamento marxista, então na moda, a Universidade de Frankfurt, mas considerou-o surpreendentemente fora do contato com as realidades da época. Preferiu então estudar direito, formando-se na Universidade de Munique e prestando o exame da ordem dos advogados em 1927. (...) Depois que se tornou professor de Direito em Madri, em 1935, o que no mundo latino como no mundo germânico abrange a política, sobreveio a guerra civil espanhola. Morgenthau, que havia se misturado com a elite republicana, não fez nenhum esforço para ir embora (...). Finalmente, como a situação ia de mal a pior, em 1937 ele tomou a melhor decisão que se lhe oferecia: emigrar para os Estados Unidos, onde ocupou por dois anos o modesto cargo de professor auxiliar de governo no Brooklyn College e experimentou a reputação, entre estudantes ativistas judeus comunistas, de ser protofascista por causa da opinião neutra e fria que tinha a respeito da política, encarando-a como Realpolitik" (HASLAM, 2006). Por conter informações geralmente ignoradas nos estudos de Relações Internacionais, cremos interessante trazer aspectos biográficos de ambos os autores em questão. Entretanto, uma vez que não constituem o foco deste trabalho, tais aspectos serão apresentados em forma de notas de rodapé.
} 
obra: baseados em Lima (2011, p. 71), é interessante que se frise que "apesar das interpretações dos manuais convencionais, que o tomam como exemplo canônico da abordagem realista, Morgenthau dá peso também aos limites impostos pela moralidade internacional e pelo direito internacional", ou seja, é interessante que se note que conjuntamente ao poder nacional de um Estado existem limitações morais e de caráter jurídico, de forma que ambos os elementos convivem de maneira a se limitarem reciprocamente.

Para se compreender o pensamento de Morgenthau, mesmo que parcialmente (como é o nosso objetivo neste breve texto), há que se partir dos princípios do realismo político proposto pelo autor (elementos estes de que também parte Lima, 2011), que contêm grande parte dos elementos que comporão a Politics among nations, cuja primeira edição data do fim da década de 1940.

É fundamental que se leiam esses princípios como "princípios racionais" de uma teoria da política. Isso quer dizer que essa teoria apenas leva em consideração uma das dimensões da natureza do homem. Nesse mesmo sentido, a obra do autor é crítica em relação ao racionalismo derivado da filosofia do século XVIII, que apresenta aspectos referentes à experiência histórica do período como "a verdade" (MORGENTHAU, 1947, p. 12). A natureza humana, para o autor, apresenta uma dimensão biológica e uma espiritual, para além da racional. Cremos que, por isso, sua teoria envolva aspectos relacionados à moralidade internacional e às aspirações ideológicas de uma nação.

Assim sendo, Morgenthau nos apresenta seis princípios do realismo político. O primeiro deles é a presença de leis objetivas sobre as quais se baseiam a política e a sociedade. Uma teoria racional é capaz de explicar a política a partir de tais leis, cujas "raízes" (termo utilizado por Morgenthau; roots, no original) se encontram na natureza humana: através do uso da razão, a teoria auxilia na atribuição de sentido às ações políticas tomadas (MORGENTHAU, 2006).

O segundo princípio é muito conhecido e se tornou, de certa maneira, um lugar-comum quando se trata do pensamento de Morgenthau: a ideia de que os interesses se definem em termos de poder. Isso separa a política de outras esferas de pensamento, uma vez que o poder é o objeto de tal campo, sem o qual se torna impossível, de acordo com o autor, a concepção de uma teoria política, seja ela internacional ou doméstica. Da mesma forma, em se tratando de uma teoria realista, há que se separar a ética da política: a ética julgará as qualidades morais dos motivos que levaram a determinada ação; para a política, o importante são as 
qualidades políticas da vontade e da ação daquele que propõe tal empresa. Assim sendo, uma ação política racional, isto é, aquela que minimiza os riscos e maximiza os benefícios dela esperados pode ser considerada uma boa ação política.

O terceiro princípio trata sobre suposição realista de interesse definido como poder: para Morgenthau, contudo, o interesse não deve ser entendido como fixo, de modo que:

a noção de interesse faz parte realmente da essência da política, motivo por que não se vê afetada pelas circunstâncias de tempo e lugar. (...) Contudo, o tipo de interesse que determina a ação política em um determinado período da história depende do contexto político e cultural dentro do qual é formulada a política externa (MORGENTHAU, 2003, pp. 16-18, grifos nossos) $)^{4}$.

O interesse é o determinante das ações humanas, ao menos em se tratando de política. Dessa forma, se, por exemplo, na economia, o interesse é definido em termos de riqueza, na política ele se compreende em termos de poder, conceito este que encerra em si tudo aquilo que estabeleça e mantenha o controle do homem sobre o homem, de modo que "o poder engloba todos os relacionamentos sociais que se prestam a tal fim, desde a violência física até os mais sutis laços psicológicos mediante os quais a mente de um ser controla uma outra" (MORGENTHAU, 2003, p. 18).

Ainda assim, contudo, o realismo político é ciente do significado de dimensão moral que as ações políticas podem tomar (MORGENTHAU, 2006, p. 12), tratando-se tal formulação do quarto princípio do realismo político. Sobre tal aspecto, embora os indivíduos possam agir através de convicções éticas e morais próprias, o Estado não tem tal direito, uma vez que tem sob sua guarda, seus cidadãos, e deve sempre buscar o sucesso de sua ação política, inspirando-se no princípio moral da sobrevivência nacional (MORGENTHAU, 2006, p. 12). Lima (2011, p. 59) traz este princípio de maneira bem sintética e precisa: "na esfera pública, os atores são julgados e avaliados pelas consequências políticas de suas ações, enquanto estadistas, e não pelo conteúdo moral de suas ações, aplicáveis à esfera do comportamento privado".

O quinto princípio trata sobre a diferenciação das aspirações morais de uma determinada nação em relação a leis morais: "assim como sabe distinguir entre a verdade e a opinião, é capaz também de separar a verdade da idolatria. Todas as nações são tentadas a vestir suas próprias aspirações e ações particulares com a roupagem dos fins morais do

\footnotetext{
${ }^{4}$ Faremos referência a MORGENTHAU (2006) quando fizermos citações indiretas, uma vez que é o texto sobre o qual nos baseamos para escrever este artigo, encontrando-se em inglês. Quando necessárias citações diretas, elas serão feitas a partir da tradução brasileira que se encontra sob a referência MORGENTHAU (2003).
} 
universo" (MORGENTHAU, 2003, p. 21). Esse princípio deixa bem claro que a política para Morgenthau define-se como uma luta pelo poder, independentemente da forma como se apresentem seus contendores.

Por fim, o sexto princípio traz explicitamente (reiterando o que de certa forma já fora sugerido anteriormente) a necessidade de se separar a esfera da política para lidar com suas relações e especificidades. Reitera-se aqui, portanto, a autonomia da esfera política, já que "uma vez que admite a existência dessas distintas facetas da natureza, o realismo político também reconhece que, para compreender qualquer uma delas, é necessário tratar de cada uma em seus próprios termos" (MORGENTHAU, 2003, p. 27).

A partir dos princípios apresentados, Morgenthau passa a teorizar sobre o poder nacional e sobre a "luta pelo poder", subtítulo de seu livro primordial. Dessa maneira, reconhece a existência de um poder nacional, a partir do qual será formulada a política externa de uma nação, visando à obtenção de poder. Nove são os elementos que constituem o poder nacional, a saber: a geografia, os recursos naturais, a capacidade industrial, o poderio militar, a população, o caráter nacional, a moral nacional, a qualidade da diplomacia e a qualidade do governo. Dessa maneira, em ambiente internacional o Estado se comportará politicamente de maneira a manter seu poder nacional, aumentá-lo ou demonstrá-lo. A estas políticas Morgenthau chama respectivamente de política do status quo, imperialismo, e política de prestígio. Não adentraremos a cada uma de suas especificidades, pois não constitui nosso objetivo neste texto. Apesar de o interesse nacional ser definido em termos de poder, a política internacional se tratar de uma luta por tal poder e o Estado possuir algumas políticas as quais ele possa querer perseguir, há limitações para o poder nacional, e estas se tratam da balança de poder, do direito internacional e da opinião pública e moralidade internacionais.

Lima (2011) compreende que para Morgenthau a natureza humana é plural, multifacetada e complexa. Contudo, uma característica de tal natureza se sobressai quando se trata de política, isto é, a luta pelo poder, e tal luta é justamente visando à dominação das mentes e ações humanas: o caráter humano egoísta e focado no interesse, porque é isso que se espera de atitudes políticas que visem ao poder. Se o poder pode ser definido como um controle sobre as ações e as mentes das pessoas, atitudes como a dissuasão são atitudes políticas, pois visam controlar a mente do rival de modo a "manipular" suas expectativas, de forma que o uso do poder material não seja necessário (LIMA, 2011, p. 63). Da mesma forma, 
Estado em relação a ouro. É sua contribuição para o poder nacional que faz de uma política governamental, qualquer que seja sua natureza, um instrumento político. Mas a aspiração pelo poder é o que diferencia a atividade política das demais, está presente em todas as relações sociais e em todos os níveis de organização social. A razão para tal tem a ver com um fenômeno presente em todas as associações humanas, da família ao Estado: a tendência a dominar (LIMA, 2011, p. 63-64).

Em Morgenthau, como dissemos anteriormente, está presente a ideia da balança de poder como limite para o poder nacional, sendo que a balança de poder é compreendida como uma distribuição de poder aparentemente igual entre os Estados. A balança de poder é usada como modo de limitação do poder nacional pelos Estados rivais, mas, ao mesmo tempo, o poder nacional deve se aumentar como forma de limitar o poder nacional dos outros Estados.

Segundo Lima (2011, p. 67), em Morgenthau temos a virtude da balança de poder como maneira de manutenção da liberdade das potências, reafirmando sua pluralidade. $\mathrm{O}$ princípio de equilíbrio de poder está presente em diversos âmbitos da vida política, sendo o mais conhecido deles, o mecanismo de checks and balances, constituinte da formulação de política externa norte-americana. A comentadora vai ainda mais fundo, e faremos uso de seu raciocínio de maneira extensiva no próximo trecho:

as práticas de compensações territoriais, redução de armamentos e formação de aliança compõem o estoque disponível de ações visando ao equilíbrio. Quando o autor discute o equilíbrio de poder como resultado não intencional da política da ação do Estado, enfatiza como uma de suas virtudes a preservação do sistema de Estados e dos Estados mais fracos no sistema. Contudo, ao examinar a operação do princípio na história, os últimos não apenas costumam ser o objeto das políticas de equilíbrio e de compensações das potências, como a eles está vedada a escolha das políticas de equilíbrio, restando apenas a aliança com um dos mais fortes para impedir ser dominado pelo outro, estratégia que realistas posteriores chamariam de bandwagoning (LIMA, 2011, p. 68).

Quanto à limitação imposta pelo direito internacional, LIMA (2011, p. 72) nos aponta que ele só seria eficaz se complementar aos interesses nacionais em jogo, e em se observando o equilíbrio entre esses interesses, o que demonstra certo ceticismo em relação a ela. Contudo, ainda de acordo com Lima (2011, p. 71), esse ceticismo não é o típico "ceticismo realista”, já que Morgenthau pauta suas observações em grande parte no princípio da eficiência, encontrada diferentemente no âmbito doméstico e no internacional: "o que diferencia a sociedade internacional das outras sociedades é o fato de que sua força - política, moral e social - está concentrada em suas unidades. Sua própria debilidade é reflexo de sua força" (MORGENTHAU, 2001, p. 92, tradução livre).

Para Morgenthau, a grande dificuldade em se estabelecer uma teoria sobre política internacional está justamente no fato da oposição ente moralidade e interesses políticos 
(MORGENTHAU, 2001, p. 96). Os interesses políticos de uma nação não devem refletir os interesses de apenas uma fração da sociedade, mas da sociedade enquanto um todo: "o período da história, em que o interessa nacional se podia definir como subordinado e limitado, foi substituído por outro em que a nação converteu-se na organização social secular mais elevada e seus interesses no foco comum de todos os interesses seculares" (MORGENTHAU, 2001, p. 96, tradução livre).

Assim, a teoria de Morgenthau busca, a partir da compreensão da esfera política como autônoma, a compreensão dos fenômenos políticos internacionais, que são extensão dos domésticos, os quais apenas são políticos porque os interesses com que eles lidam são tomados em termos de poder: a política é a luta pelo poder e uma teoria racional da política visa a, através da razão, buscar o sentido das ações tomadas. Dessa forma, Morgenthau nos informa num trabalho de 1962, chamado de The commitments of a theory of international politics:

\begin{abstract}
o interesse nacional definido em termos de poder, a incerteza precária do equilíbrio internacional do poder, a debilidade da moralidade internacional, o caráter descentralizado do direito internacional, a decepção das ideologias, as contradições internas da organização internacional, o controle democrático da política exterior, os requisitos da diplomacia, o problema da guerra: a teoria deve ter presentes todos esses fenômenos e problemas da política que aparecem na cena internacional em manifestações peculiares, devido ao caráter igualmente peculiar da sociedade internacional (MORGENTHAU, 2001, p. 92, tradução livre).
\end{abstract}

Essas são as manifestações do fenômeno da política presentes no campo, sobre que uma teoria de política internacional nos deve informar, segundo Morgenthau. Cerca de trinta anos após o lançamento da primeira edição da principal obra do autor alemão radicado nos Estados Unidos, Kenneth Waltz publicaria a sua obra principal, Theory of international politics. Sobre o pensamento de Waltz nos ocuparemos na próxima seção.

\title{
Kenneth Neal Waltz: A política internacional e sua estrutura
}

O pensamento de Kenneth Waltz ${ }^{5}$ inaugura aquilo que didaticamente se convencionou chamar de "terceiro debate" da disciplina de relações internacionais: é em torno de sua obra theory of international politics (1979) que se darão as discussões sobre a abordagem teórica mais profícua para se estudarem as relações internacionais, reunindo de um lado os

\footnotetext{
5 "Waltz, filho de americanos que falavam alemão, da classe operária, nasceu em Ann Arbor, Michigan, em 8 de junho de 1924. Formou-se no Oberlin College em 1948. Entrou para a pós-graduação em Colúmbia (...). A tese, defendida na Columbia University em 1954, recebeu o título de O homem, o Estado e o sistema de Estados nas teorias sobre as causas da guerra" (HASLAM, 2006, 383-384). O autor falece em 2013.
} 
neorrealistas e, do outro, aqueles contrários ao pensamento neorrealista - ou realista estrutural ${ }^{6}$.

Segundo HALLIDAY (1999), embora a obra mais conhecida de Waltz seja a de 1979, sua reputação enquanto estudioso das relações internacionais - e da política internacional, em sentido mais estrito - se consolida ao menos um quarto de século antes, quando da publicação de sua tese de doutoramento sob o nome de Man, the state, and War: a theoretical analysis, em que Waltz se propõe a sistematizar o pensamento de estadistas, filósofos e cientistas políticos acerca de quais seriam as causas da guerra. A esta pergunta, diversas respostas são dadas $^{7}$, sendo possível agrupá-las sob três "tópicos", a que Waltz chamará "imagens" das relações internacionais, já que a palavra "imagem" "suggests that one views the world in a certain way" (WALTZ, 2001, p. ix): as imagens são a natureza humana (primeira imagem), a estrutura doméstica dos Estados (segunda imagem) e a anarquia internacional (terceira imagem). De acordo com Griffiths (1999, p. 47), Man, the state, and War contém os elementos mais básicos que serão completamente desenvolvidos na Theory of International Politics, o que nos permite pensar a obra do autor como um contínuo, com formulações metodológicas mais complexas, mas mantendo os elementos conceituais mais fundamentais.

Em Theory of International Politics, Waltz proporá que há dois tipos de teorias que lidam com os fenômenos que acontecem internacionalmente, de acordo com a maneira como organizam seus materiais de pesquisa e suas ideias: teorias reducionistas e teorias sistêmicas o autor vai ainda mais longe, dizendo que sua tentativa na obra de 1979 é justamente o estabelecimento de uma teoria sistêmica da política internacional. Ora, mas do que se trata dizer que uma teoria é sistêmica? É aquela que explica os resultados de acordo com a influência de um sistema sobre as unidades que o compõem:

num nível, um sistema consiste de uma estrutura, e a estrutura é o componente a nível do sistema que torna possível pensar das unidades como formando um conjunto distinto de uma simples coleção. Em outro nível, o sistema consiste de unidades que interagem. O objetivo de uma teoria sistêmica é mostrar como os dois

\footnotetext{
${ }^{6}$ Waever (2008) faz, entretanto, uma divisão heterodoxa dos debates das teorias de relações internacionais, dividindo este terceiro debate em dois momentos: primeiro, um debate interparadigmático entre neorrealistas e liberal-insitucionalistas (ou neoliberais); e, num segundo momento, após uma síntese neo-neo, entre racionalistas (que incluiria o pensamento resultante da síntese entre neorrealistas e neoliberais) e reflexivistas, contrários à primeira abordagem. Embora consideremos a abordagem do autor dinamarquês mais detalhada em alguns aspectos, valendo citar-se sua divisão, nos utilizaremos da visão tradicional que enunciamos no corpo do texto.

${ }^{7}$ Em entrevista concedida a Fred Halliday e Justin Rosenberg, Waltz diz que sua ideia das três imagens vem da leitura dos diversos escritos desses estadistas, filósofos e cientistas políticos: "this is why the people I am reading are not able to communicate with each other: because some of them think the major causes lie at the level of individuals or states or international system" (HALLIDAY, ROSENBERG, 1998). A mesma explicação é narrada no prefácio à edição de 2001 de Man, the state, and War.
} 
níveis operam e interagem, e isso requer diferenciá-los um do outro (WALTZ, 1979, p. 40 , tradução livre).

Nesse sentido, como apontado por John RUGGIE (1983) o sistema internacional seria um fato $\operatorname{social}^{8}$, já que, baseado em Durkheim, ele é exterior às unidades da sociedade que compõe, e não sujeito a transformações por mero esforço das ditas unidades. WALTZ (1986), em resposta a Ruggie, parece concordar com as influências do pensamento de Durkheim para sua obra.

Para Waltz, com o propósito de se lidar didaticamente com a realidade, há que se isolála. Assim, uma teoria que vise a analisar fenômenos políticos, deve isolar o âmbito político para a verificação das causas e efeitos de ditos fenômenos, já que uma teoria, na concepção que lhe atribui Waltz, deve ser sobre alguma coisa, e não sobre tudo (HALLIDAY, ROSENBERG, 1998). Dessa forma, Waltz pressupõe um isolamento da esfera política da realidade, usando como unidade os Estados, uma vez que seu objetivo aqui é o estabelecimento de uma teoria de política internacional. Sobre isso, sintetizando o que dissemos, o autor aponta que:

os Estados não são e nunca foram os únicos atores internacionais. Mas estruturas se definem não através de todos os atores que nelas florescem, mas através dos principais. Em se definindo a estrutura de um sistema escolhem-se um ou alguns dos muitos objetos que o compõem e se define a estrutura em seus termos. Para sistemas políticos internacionais, como para qualquer sistema, deve-se primeiramente decidir quais unidades tomar como sendo partes dele (WALTZ, 1979, p. 93, tradução livre).

Ora, se no pensamento de Waltz a estrutura tem um papel tão importante, como é que podemos defini-la? A estrutura é o conceito que, segundo Waltz, nos faz conceber o sistema internacional como um todo. A estrutura, junto as unidades que interagem, são o que compõem o sistema internacional no pensamento do cientista político norte-americano. Isolando-o para melhor compreendê-lo (assim como faz Waltz em sua obra), temos que o conceito de estrutura, de ordem extremamente abstrata, é composta por três elementos: 1) os princípios organizadores da estrutura, que é basicamente a anarquia do sistema internacional, e o sistema que se desenvolve aqui é um do tipo self-help, em que os Estados buscarão sua

\footnotetext{
${ }^{8}$ Originalmente, segundo o pensador francês Émile Durkheim "é fato social toda maneira de fazer, fixada ou não, suscetível de exercer sobre o indivíduo uma coerção exterior; ou ainda, toda maneira de fazer que é geral na extensão de uma sociedade e, ao mesmo tempo, possui uma existência própria, independente de suas manifestações individuais" (DURKHEIM, 2007, p. 12). Portanto, para o autor francês, os fatos sociais apresentam "características muito especiais: consistem em maneiras de agir, pensar e de sentir, exteriores ao indivíduo, e que são dotadas de um poder de coerção em virtude do qual esses fatos se impõem a ele" (DURKHEIM, 2007, p. 3). No caso da analogia identificada pro John Ruggie, os indivíduos de que trata Durkheim seriam, internacionalmente, os Estados. É importante notar que Durkheim é uma referência na produção teórica desde 1959, estando presente também em sua principal obra vinte anos depois.
} 
própria sobrevivência, ainda que esta se dê em detrimento da sobrevivência de outrem - a sobrevivência do Estado é a base para qualquer ação do Estado em ambiente anárquico; 2) $o$ caráter das unidades, isto é, o sistema é composto de unidades soberanas, ou seja, que definem por si mesmas como lidar com seus desafios internos e internacionais, o tratamento de Estados como unidades implica em considerá-los todos iguais, submetidos às mesmas tarefas, que podem desempenhar com maior ou menor habilidade, o que, para Waltz, é o mesmo que dizer que os Estados são soberanos; e 3) a distribuição das capacidades entre as unidades, tratando-se tal princípio de um atributo sob regência da estrutura e das unidades, são as capacidades que fazem com que um Estado seja melhor ou pior sucedido em suas tarefas: é a distribuição das capacidades que nos faz pensar em polos de poder, que são definidores da estrutura enquanto unipolar, bipolar, ou multipolar.

O filósofo que dá embasamento teórico para a terceira imagem (em que Waltz baseará, então, sua teoria sistêmica da política internacional) é o genebrino Jean-Jacques Rousseau. Rousseau, em seus escritos sobre política doméstica e internacional propõe a existência da vontade geral, ou seja, o determinante de ação dos Estados. Enquanto podemos falar de vontade geral domesticamente devido à existência de um povo que possui o poder soberano daquele Estado, internacionalmente não há um poder soberano único, mas diversos povos, que determinam a vontade geral de seus Estados. Dessa forma, em ambiente internacional, as "vontades gerais" de cada um dos Estados soberanos tendem a ser encaradas como vontades particulares, e este estado de ausência de uma vontade geral, por assim dizer, harmonizadora, pode levar à guerra. A guerra somente pode existir entre Estados (entes morais), e nunca entre indivíduos, daí o absurdo em se falar, na teoria de Rousseau, em estado de guerra entre indivíduos como situação anterior ao estado civil ${ }^{9}$. Em seu escrito $O$ Estado de Guerra Nascido do Estado Social, Rousseau deixa clara esta disposição existente entre os Estados:

assim, chamo de guerra entre potências o resultado de uma disposição clara, constante e recíproca de destruir o Estado inimigo, ou pelo menos de debilitá-lo por todos os meios possíveis. Quando essa disposição se transforma em ação, temos a guerra propriamente dita; na medida em que não se dá a transformação, temos apenas um "estado de guerra" (ROUSSEAU, 2001, p. 53).

Nesse sentido, valendo-nos da existência de um cenário internacional anárquico, temos a presença, segundo Waltz, deste constante estado de guerra, em que nada há que evite os conflitos de ocorrerem - e esta é uma consequência da terceira imagem para Waltz. Mais um

\footnotetext{
9 “A guerra não é uma relação entre indivíduos, mas entre Estados, que só por acidente faz com que as pessoas se tornem inimigas, menos como cidadãos do que na condição de soldados” (ROUSSEAU, 2001, p. 66).
} 
ponto esboçado por Rousseau serve para a teorização waltziana, a saber: "a guerra nasce da paz, ou, pelo menos, das precauções tomadas pelos homens para garantir uma paz duradoura" (ROUSSEAU, 2001, p. 57). Para Waltz é aproximadamente nestes termos que se dá a formação da balança de poder: esta se forma quando da existência de apenas duas condições, quais sejam, a existência de um ambiente anárquico e a existência de unidades que desejem sobreviver. Ao buscar causas na própria política internacional para fenômenos que acontecem nesse campo, Waltz advoga, portanto, em direção à sua autonomia. Partindo da ideia de autonomia da política encontrada em Maquiavel (WALTZ, 1975, 1979), Waltz constrói portanto "a especificidade do sistema de relações internacionais - a ordem da anarquia" (GASPAR, 2013, p. 8).

Podendo basear-se apenas em suas próprias capacidades, as unidades tenderão a aprimorar suas capacidades cada vez mais, visando à sua própria sobrevivência. Deste contexto, a balança de poder emerge - ou seja, dois ou mais polos com poder aproximado (sendo a distribuição desses poderes, como já dissemos, um atributo do sistema) passam a definir, não intencionalmente, a estrutura do sistema, que passará a encorajar alguns comportamentos e a punir outros, inclusive para as grandes potências. Isso explica o porquê de ações iguais no sistema internacional terem resultados diferentes, e ações diferentes que possam vir a ter resultados iguais, e é por essa razão que Waltz considera importante uma abordagem sistêmica para a política internacional, já que isso seria um indicativo de ação de forças sistêmicas, que se originam pela simples coexistência das unidades no sistema (WALTZ, 1975, 1979, 2001). Os Estados que são polos da estrutura tenderão à manutenção de sua posição, e os demais Estados tenderão a se socializarem com as "regras" da estrutura que está colocada: "a disposição das unidades no sistema condiciona os tomadores de decisão dos países a uma similaridade de decisões e condutas de suas políticas externas que devem pouco para as considerações políticas nacionais e pessoais" (DUARTE, CAMPOS, 2013, p. 66, grifo nosso). Perceba-se o termo grifado (“condiciona”), que é importante: a estrutura do sistema não determina as ações que serão tomadas pelos Estados (WALTZ, 1996), entretanto lhes apresenta constrangimentos sérios a serem considerados.

A estrutura da política internacional, se funda no "princípio ordenador" da anarquia, diferentemente da política doméstica que se funda no da hierarquia. Mudando-se da anarquia para a hierarquia temos uma mudança de sistema - mudança esta que não se vislumbra na política internacional. Por isso, a estrutura do sistema internacional somente muda em se 
mudando a distribuição das capacidades entre suas unidades. Nesse sentido, apontam Duarte, Campos (2013) que a anarquia é a grande ideia proveniente da disciplina de Relações Internacionais, que se apresenta na obra de Waltz como "elemento fulcral".

Dessa forma, a balança de poder surge como um resultado não intencional, da mesma maneira que a estrutura não é intencional, mas um resultado do acúmulo de capacidades por algumas unidades, capacidades estas incapazes de serem sobrepostas, de onde vem a formação de polos no sistema. Em linhas gerais, o neorrealismo de Kenneth Waltz trata dos assuntos de política internacional nestes termos. Waltz, metodologicamente, recorre à economia para trazer contribuições para a política internacional - daí que é perfeitamente possível a analogia entre o mercado e a estrutura do sistema internacional, ou entre os Estados e as firmas, pois é exatamente desta analogia que partiu a proposta metodológica de Waltz. O autor tenta, portanto, estabelecer uma teoria de política internacional geral o suficiente para ter serventia para qualquer período histórico - havendo unidades e um sistema internacional anárquico, a balança de poder surgirá: esta é uma regularidade que recorre como uma lei da política internacional, e é em torno desta regularidade que Waltz estabelece sua teoria.

\section{Morgenthau e Waltz: Uma tentativa de comparação}

Embora Morgenthau e Waltz apresentem muitas semelhanças, o que leva a que ambos sejam considerados autores de vertente realista nas relações internacionais, como consideram Halliday e Grieco, encontramos algumas divergências, advindas principalmente do próprio Waltz, já que o autor norte-americano, segundo Cepik, Schneider (2011, p. 109), "recusa como inconsistente e sem sentido a ideia de um 'paradigma realista' que poria o seu programa de pesquisa e o de Hans Morgenthau, por exemplo, sob um mesmo teto intelectual”. Contudo, afirmamos novamente como já fizemos na introdução, é indubitável que ambos os autores apresentem semelhanças.

Para ambos os autores há leis objetivas, passíveis de compreensão e de estudo acadêmico: isso constitui um princípio do realismo político para Morgenthau, enquanto constitui, para Waltz, uma maneira de se conceber a ciência, que dará suporte para a emergência de sua teoria de política internacional. Para Waltz a teoria explicará as leis através da formação de conceitos. Não é esta a pretensão de Morgenthau: ao afirmar a existência dessas leis objetivas, o autor diz que elas "deitam suas raízes" na natureza humana, que, apesar de complexa, apresenta algumas regularidades quando se trata de interesses definidos 
em termos de poder (ou seja, fenômenos políticos). Basear uma teoria de política internacional numa dada natureza humana não constitui, para Waltz, uma ciência da política internacional, não no sentido estrito (que, neste sentido, deve ser entendido como "sistêmico") do termo. No sentido inverso, Morgenthau rejeitaria a ideia fundamental de Waltz de basear sua teoria nos moldes das ciências naturais (HALLIDAY, ROSENBERG, 1998), enxergando tal situação como um resquício da filosofia originada no século XVIII, clamando por uma certeza que não pode ser obtida nem mesmo pelas ciências duras (MORGENTHAU, 1947). Assim, buscar o sentido da "objetividade" proposta por Morgenthau poderia clarificar melhor seus referenciais fundamentais.

No segundo princípio do realismo político elaborado por Morgenthau, podemos encontrar, talvez, uma consonância da obra de ambos os autores. Morgenthau separa o campo da ética do da política; ao passo de que Waltz nem chega a tratar sobre o assunto em Theory of international politics; enquanto em man, the state, and war, o autor classifica os autores da primeira e segunda imagem como autores que se guiam por princípios morais, mas que tais princípios não são definidores da guerra e da paz: o que torna a guerra inevitável é que nada existe que a impeça de ocorrer, ou seja, a causa permissiva dos conflitos internacionais (a saber, a anarquia internacional). Ambos parecem convergir também com o julgamento que se pode dar a uma ação política: ela deve ser avaliada pelas suas consequências políticas, e não morais (no caso de Morgenthau, o aumento do poder nacional; para Waltz, o cálculo que faça com que o sistema internacional continue com a configuração em que se encontra, com o Estado motivador da ação política ainda sobrevivendo).

Quanto ao terceiro princípio de que trata Morgenthau, temos que a política é o âmbito da luta pelo poder, já que os interesses na política se definem em termos de poder, como afirmamos baseados no autor. A luta será sempre pelo interesse, sendo que este é definido de acordo com características culturais e políticas do contexto histórico em que encontramos o caso estudado. Já para Waltz, o interesse do Estado será sempre a sua própria sobrevivência, sendo que esta é uma assunção do autor que dá origem a toda sua teoria ${ }^{10}$. O poder pode até ser buscado, mas ele o será sempre como um meio para que se atinja o objetivo do Estado, sendo que tal objetivo será sempre, em última instância, a sobrevivência do mesmo. Ainda em tal princípio, podemos encontrar mais uma divergência entre ambos os autores: para

\footnotetext{
${ }^{10}$ Em 1959, Waltz apresenta a sobrevivência como uma necessidade lógica: qualquer que seja o objetivo do Estado, ele precisa existir para obtê-lo (WALTZ, 2001). Já a partir de 1975, a sobrevivência torna-se uma "assunção", ou seja, uma afirmação não-factual que tem por função permitir a construção de uma teoria (WALTZ, 1975, 1979).
} 
Morgenthau, a luta pelo poder enquanto fenômeno da política não diferenciará, portanto, a política doméstica da política externa: ambas se resumem à luta pelo poder, os interesses são definidos em termo deste conceito, a luta é pela busca do controle sobre as mentes e as ações humanas, como expressado literalmente pelo autor. Já para Waltz, o simples fato de o sistema internacional ser anárquico já é um enorme diferenciador do sistema doméstico do internacional. A anarquia é o ponto de partida das observações de Waltz, de tal maneira que constitui inclusive um dos elementos para a definição de estrutura internacional, conceito com o qual Waltz elabora a maior parte de suas teorizações. Para Morgenthau, a ausência de governo em ambiente internacional é um dado, e os Estados continuam a perseguir seus interesses (em termos de poder) mesmo neste ambiente anárquico. No pensamento de Waltz, a anarquia condiciona grandemente o comportamento dos Estados, inclusive para a formação da balança de poder, tal é seu foco em tal conceito.

No sentido do que acabamos de afirmar, é simples compreender o que Waltz quer dizer quando afirma que o realismo clássico ("old realism”, no orginal) é behaviorista: suas conclusões são baseadas apenas no comportamento dos Estados (WALTZ, 2004, p. 3). Nesse sentido, trata-se de uma teoria reducionista, pois não concebe o sistema internacional como um elemento alheio à vontade dos Estados, formado por uma estrutura que surge não intencionalmente: "o sistema internacional, se chega a ser concebido, é tomado como sendo apenas um resultado" (WALTZ, 1979, p. 60, tradução livre). Se tomarmos a concepção de Morgenthau sobre política internacional e Estados que perseguem seu interesse através de relações de poder, realmente, o sistema internacional em Morgenthau é um mero resultado das atuações daqueles que o compõem, partindo da concepção Waltziana, já que "uma teoria sobre a política externa é uma teoria a nível nacional” (WALTZ, 1979, p. 72, tradução livre).

Ambos Morgenhau e Waltz apresentam uma concepção muito próxima de política externa, embora para a compreensão da política internacional de Waltz não seja necessária uma teoria de política externa, segundo o próprio autor. Ambos compreendem que a política externa de um país deve ser única, apresentar interesses de ordem geral, de modo que contemple a todos os segmentos que compõem o Estado, nesse sentido, sendo precisa a observação de Grieco (1997), segundo quem, para o realismo, o Estado é concebido como um ator racional, autônomo e unitário em suas ações. Diz Morgenthau que a política externa de um país não deve refletir o interesse de uma única fração da sociedade, mas da sociedade como um todo, como já citamos acima (MORGENTHAU, 2001, p. 96). Para Waltz, embora 
(frisemos novamente), a política externa compõe parte do estudo da política doméstica, e não um objeto de estudo do teórico da política internacional, sua concepção é a de que "se temos um Estado, temos uma política exterior, e na política exterior o Estado deve falar com uma só voz" (WALTZ, 2001, p. 179, tradução livre). Para Morgenthau, e não temos registros quanto à concepção de Waltz a respeito disso, a política externa não deve estar sujeita à aprovação da maioria da população, como as demais políticas públicas:

ela pertence ao núcleo do Estado e, portanto, não pode estar sujeita à volatilidade da opinião pública. A questão encontra ressonância entre os autores realistas que, ao contrário dos liberais, argumentam que o Estado representativo-democrático moderno necessita para seu funcionamento de áreas cinzentas não sujeitas ao controle da maioria. A política externa é uma política de Estado e não de governo (LIMA, 2011, p. 66).

Voltando aos princípios do realismo político de Morgenthau, onde baseamos nossas observações comparativas entre ambos os autores, temos o quarto princípio, a tratar novamente da dimensão moral e política das ações do Estado. Morgenthau, aqui, afirmará que os princípios que devem guiar uma ação política de sucesso baseiam-se na sobrevivência da nação, algo muito próximo do princípio de sobrevivência do Estado de que Waltz tratará alguns anos depois. Se o objetivo do Estado é buscar seus interesses (entendidos em termos de poder) para a manutenção do Estado, também é este o princípio de que parte Waltz para suas observações: "o motivo da sobrevivência é tomado mais como o princípio de ação num mundo em que a segurança dos Estados não está garantida, do que como uma descrição realista do impulso que se encontra por detrás de todos os atos do Estado" (WALTZ, 1979, p. 92, tradução livre, grifos nossos). No excerto anterior, embora Waltz possa esboçar uma diferenciação entre o realismo clássico e sua teoria de política internacional, temos que o princípio da sobrevivência do Estado também está presente no pensamento de Morgenthau, de maneira que a ação política do Estado é "ela própria inspirada pelo princípio moral de sobrevivência nacional" (MORGENTHAU, 2003, p. 20).

No que diz respeito ao quinto princípio do realismo político de Morgenthau, seu objetivo é a diferenciação entre aquilo que pode ser objetivamente estudado (no caso, as aspirações de poder de um dado Estado) e a ideologia, que o Estado pode usar para justificar a sua busca por poder. Waltz parece compartilhar desse princípio, no sentido de desnudar as capacidades de um Estado, de modo a analisá-lo enquanto um polo de poder ou não, já que são os polos de poder que definem a estrutura do sistema internacional. Nesse sentido, nos dirá Waltz que: 
para definirem-se estruturas políticas internacionais, tomamos os Estados com quaisquer tradições, hábitos, objetivos, desejos e formas de governo que possam ter. Não perguntamos se são revolucionários ou legítimos, autoritários ou democráticos, ideológicos ou pragmáticos. Abstraímos de todos os atributos dos Estados, com exceção de suas capacidades (WALTZ, 1979, p. 99, tradução livre).

O que vemos diante de nós, portanto, é, em ambos os autores, um desnudamento das capacidades do Estado e de seu poder, em virtude de lidar objetivamente com suas ações e os resultados que se encontram no sistema internacional: as ideologias, a cultura, as formas de governo não são passíveis de análise objetiva em se tratando de seus resultados. Dessa maneira, em busca de uma ciência da política internacional, ambos os autores desconsideram alguns "adornos" do Estado, desnudando suas principais potencialidades.

O sexto princípio, que versa sobre a autonomia da política, é, talvez, o ponto em que encontramos maior consonância em ambos os autores. Se, como já citamos, visando à compreensão de uma faceta da natureza humana, temos que lidar com ela em seus próprios termos como expressa Morgenthau visando ao tratamento da política por seus próprios termos (poder), Waltz também apresenta a mesma tendência para a elaboração de sua teoria de política internacional: as teorias isolam certa parcela da realidade para lidar inteligivelmente com elas, de maneira que "uma teoria, ainda que relacionada ao mundo sobre o qual as explicações se desejam, sempre permanecem distintas desse mundo (...). Teorias realmente constroem uma realidade, mas não se pode jamais dizer que ela seja $a$ realidade" (WALTZ, 1979, p. 6-9, tradução livre).

Outro ponto que muito nos chama atenção em ambas as teorias é a existência da balança/equilíbrio de poder. Para Morgenthau, elas são uma maneira de evitar que o Estado rival (ou os Estados rivais) se torne tão forte que não possa ser impedido de dominar os outros. O princípio é o mesmo para Waltz, já que a ampliação de capacidades dos Estados, e suas políticas externas podem ter consequências não esperadas em âmbito sistêmico. Entretanto, se para Morgenthau a balança de poder é uma maneira de o Estado se defender intencionalmente, para Waltz ela surge como uma consequência do sistema internacional, já que a distribuição das capacidades entre as unidades do dito sistema não é de sua espontânea vontade. Da mesma maneira, aos Estados “menores" (que, para Morgenthau, são aqueles com menor poder nacional, enquanto para Waltz são aqueles que não constituem os polos da estrutura do sistema), não lhes é conferida nenhuma chance de participar de tal equilíbrio de poder enquanto sujeitos. Para Waltz, devido às desigualdades apresentadas pelos Estados no âmbito de suas capacidades os "consequential states" têm um número reduzido, de maneira 
que são eles que formam a balança de poder, que é, em seu pensamento, constante no sistema internacional, e não uma política perseguida quando do fortalecimento de um dito Estado: nesse sentido, qualquer teoria de política internacional deve dar-se em termos das grandes potências, que estarão na estrutura do sistema, tornando-o unipolar, bipolar ou multipolar, ou seja, "a política internacional é necessariamente um sistema de números pequenos" (WALTZ, 1979, p. 192, tradução livre). Contudo, se por um lado, o comportamento de bandwagoning (o qual ainda não está presente no horizonte analítico de Morgenthau) é tudo o que resta aos Estados menores, Waltz dirá que o comportamento que se espera de um Estado não é tal, é sempre o de balanceamento, pois todas as unidades estão imersas num sistema do tipo selfhelp, em que se pode confiar apenas em suas próprias capacidades para sua própria sobrevivência. Nesse sentido, o ambiente anárquico internacional constrange os Estados para um balanceamento, de tal forma que, aparentemente, a escolha que se coloca é entre a sobrevivência e a (possível) destruição - os riscos são demasiadamente altos para não se conformar àquilo que se apresenta como mais seguro.

\section{Considerações finais}

Muito longe de pretendermos esgotar o assunto das aproximações e distâncias entre os pensamentos de Morgenthau e Waltz, o que buscamos aqui foi tentar elucidar alguns desses pontos, sempre buscando aproximações e distanciamentos. Há muitos pontos em comum entre ambos os autores, permitindo que ambos tomem a alcunha de "realistas", ainda que o termo em seu sentido puro seja impróprio, pois Morgenthau, por exemplo, o grande ícone do realismo, apresenta algumas características que podem ser consideradas idealistas, embora sua formulação seja diferente, como a questão da moralidade e do direito internacionais. Já em Waltz fica muito mais difícil encontrar tais características, o que não quer dizer que isso seja impossível.

Há, contudo, diversas diferenças entre as abordagens de ambos os autores, que faz com que não seja sem fundamento a abordagem de Waltz que o separa de outros autores considerados realistas. O realismo de Waltz apresenta um caráter muito mais, por falta de termos melhores, "realista" em sentido estrito que o de Morgenthau. Aliás, o próprio Waltz trata a teoria de Morgenthau como uma teoria "behaviorista", no sentido de não conceber um sistema internacional que surja não intencionalmente, como um "subproduto" do comportamento dos Estados; o "internacional” para Morgenthau, segundo Waltz o lê, é uma 
mera resultante das políticas externas dos Estados, sendo que a política externa, no pensamento de Waltz, diz mais respeito à estrutura do Estado que ao nível sistêmico da política internacional.

Ambos os autores são importantes para a compreensão dos fenômenos internacionais. Talvez, uma forma de uni-los seja justamente a partir da complementaridade de seus temas: por exemplo, a compreensão da política externa não está no horizonte pretendido por Waltz, mas está no de Morgenthau. Se ambos os autores partem de premissas ao menos semelhantes, não seria absurdo a tentativa de usar ambas as teorias em conjunto, talvez numa tentativa experimental de saber se tal conjunção é ou não possível.

\section{Referências bibliográficas}

CEPIK, Marco; SCHNEIDER, Luiza. "Kenneth Waltz". In: MEDEIROS, Marcelo de Almeida; LIMA, Marcos Costa; VILLA, Rafael; REIS, Rossana Rocha (Org). Clássicos das relações internacionais. São Paulo: Hucitec, 2011, pp. 92-116.

DUARTE, Érico Esteves; CAMPOS, Tiago Cerqueira. Waltz, a ideia de anarquia e o estudo das relações internacionais. Relações Internacionais, 2013, pp. 63-66.

DURKHEIM, Émile. As regras do método sociológico. São Paulo: Martins Fontes, 2007.

GASPAR, Carlos. “Waltz, Morgenthau e Aron”. Relações Internacionais, 2013, pp. 5-13.

GRIECO, Joseph M. Anarchy and the limits of cooperation: a realist critique of the newest liberal institutionalism. In: BALDWIN, David A (Editor). Neorealism and neoliberalism: the contemporary debate. New York: Columbia university Press, 1993, pp. 116142.

Realist international theory and the study of world politics. In: DOYLE, Michael; IKENBERRY, G. John (editors). New thinking in international relations theory. Oxford: Westview Press, 1997, pp. 163-201.

GRIFFITHS, Martin. Fifty Key thinkers in International Relations. Londres: Routledge, 1997.

HALLIDAY, F. Repensando as relações internacionais. Porto Alegre: Editora UFGRS, 1999.

HALLIDAY, Fred; ROSENBERG, Justin. 1998. Interview with Kenneth Waltz. Review of international studies, 24, 3, 1998, 371-386.

HASLAM, Johnatan. A necessidade é a maior virtude: o pensamento realista nas relações internacionais. São Paulo: Martins Fontes, 2006.

HOFFMANN, Stanley (edt). Teorías contemporáneas sobre las relaciones internacionales. Madri: Tecnos, 1963. 
LIMA, M. R. S. "Morgenthau e o realismo político". In: MEDEIROS, Marcelo de Almeida; LIMA, Marcos Costa; VILLA, Rafael; REIS, Rossana Rocha. Clássicos das relações internacionais. São Paulo: Hucitec, 2011, pp. 55-76.

MEARSHEIMER, John J. "Realism, the Real World, and the Academy". In: BRECHER, Michael; HARVEY, Frank (edts.). Realism and Institutionalism in International Studies. Ann Arbor: The University of Michigan Press, 2002, pp. 23-33.

MORGENTHAU, H. J. Scientific man versus power politics. Londres: Latimer House Limited, 1947.

Politics among nations: the struggle for power and peace. Boston: McGraw-Hill Higher Education, 2006.

Los compromisos de uma teoría de la política internacional. In: MORGENTHAU, H.J. Escritos políticos. Madrid: Tecnos, 2001.

ROUSSEAU, J. J. “O Estado de guerra nascido do estado social”. In: ROUSSEAU, J. J. Rousseau e as Relações Internacionais. São Paulo: Imprensa Oficial do Estado; Brasília: Universidade de Brasília, Instituto de Pesquisa de Relações Internacionais, 2002, pp. 45-60.

RUGGIE, John G. Continuity and transformation in the world polity: toward a neorealist synthesis. World Politics, 35, 2, 1983, pp. 261-285.

WAEVER, Ole. "Figures of international thought: introducing persons instead of paradigms". In: WAEVER, Ole; NEUMANN, Iver B. The Future of International Relations: Masters in the Making? Londres: Routledge, 1997, pp. 1-40.

"The rise and fall of the inter-paradigm debate". In: SMITH, Steve; BOOTH, Ken; ZALEWSKI, Maysia (Editors). International theory: positivism and beyond. Cambridge: Cambridge University Press, 2008, pp. 149-185.

WALTZ, Kenneth Neal. "Theory of international relations". In: GREENSTEIN, Fred I.; POLSBY, Nelson W. Handbook of political science: volume 8: international politics. Londres: Addison-Wesley Publishing Company, 1975, pp. 1-85.

Theory of international politics. New York: McGraham Hill, 1979.

Reflections on theory of international politics: a response to my critics. In: KEOHANE, Robert O. (editor). Neorealism and its critics. New York: Columbia University Press, 1986, pp. 255-300. 54-57.

International politics is not foreign policy. Security Studies, vol. 6, n. 01, 1996, pp.

Man, the state, and war: a theoretical analysis. New York: Columbia University Press, 2001. $2-6$.

Neorealism: Confusions and Criticisms. Journal of Politics and Society,15, 2004, pp. 
Recebido em: Julho de 2017 Aprovado em: Dezembro de 2017 